\title{
The Influence and Countermeasures of New Media on Campus
}

\section{Culture Construction}

\author{
Yao Huang ${ }^{1}$, Hui Pan ${ }^{2}$,Ruixiang $\mathrm{Ou}^{2}$, Feng $\mathrm{Pan}^{3}$ \\ ${ }^{1}$ Department of Propaganda, Party Committee, Southern Medical University, \\ Guangzhou 510515, China \\ ${ }^{2}$ South China University of Technology Library, Guangzhou, 510640, China \\ ${ }^{3}$ Finance Department of South China University of Technology, Guangzhou, \\ 510640, China
}

Key words: New media; campus culture; cultural construction; strategy research Abstract: With the continuous development of electronic information technology, the information channels gradually change from the traditional media to the new media. The new media directly or indirectly affect the ideological behavior and value orientation of teachers and students, which not only widen communication channels of students, but also make negative impact. This paper expounds the relationship between the new media and the campus culture construction, analyzes the positive influence and the negative influence of the new media on the campus culture construction, and puts forward the countermeasures to improve the campus culture construction in the new media environment according to the analysis result.

\section{The Relationship between New Media and Campus Culture Construction}

The new media provides new opportunities and challenges for the construction of campus culture, and the campus culture plays a subtle role in the ideological and political education of college students. Good campus culture can enhance the moral cultivation, ideological progress and quality improvement of college students, but also enhance the effect of ideological and political education. College students can learn professional knowledge, learn the latest theoretical results, absorb the outstanding domestic and international cultural achievements, and constantly provide ideological and political education for college students to strengthen the spiritual and cultural construction of campus by the feature that information dissemination fast and rich content of new media.

\section{The Positive Influence of New Media on Campus Culture Construction}

\section{(1) Expand the campus culture construction platform}

The new media in university contains not only computer-based campus network, educational, teaching, student management system, as well as APP that based mobile terminal. New media has a public opinion-oriented function, which has a leading role for the campus's major activities, the mainstream culture of the community. It characteristic with strong publicity, which is an important channel of the school and manager's all-round, three-dimensional propaganda campus culture, social culture, national culture. New media has the function of expanding environmental culture. It vividly shows the school building group style through the creation of micro-column, micro-video. 


\section{(2) Enrich the contents of the campus cultural activities}

New media makes campus culture spread more diversity, immediacy, and sharing. University managers on the one hand use the advantages of the new media platform for the campus cultural activities to promote and carry out a variety of channels, on the other hand actively promote the school's historical traditions, campus news and information, school community wonderful cultural activities to teachers and students by public opinion-oriented functions of new media , so that students make more comprehensive understanding of the school's culture and spirit, quickly into the school's cultural activities.

Campus cultural activities can use its diverse forms of the new media platform to meet the needs of college students, enhance the campus culture of communication and influence. Students can be able to discuss, message, and comments, which also cultivate the independent thinking ability through the new media platform .Teachers through the new media platform to carry out live seminars, lectures live, breaking the traditional fixed time and place restrictions. As the new media communication forms and content diversity, students according to their own time and interest selective viewing, which greatly promote the campus culture, improve the influence of campus culture.

\section{(3)Expand the way of college students 'getting information}

The main channel for college students to obtain information is mobile media; mobile media has a convenient, powerful, rapid spread of the characteristics, which make students the first time get news. New media technology keep pace with the times to help students understand academic knowledge, obtain academic information, and it makes learning materials more enrich and network free courses emerge, facilitate students to learn through the media terminal anytime and anywhere ;Students through the new media face a lot of unknown areas to find their own content of interest, to stimulate the enthusiasm of independent learning, what's more, student can share with more like-minded students to discuss and share, to enhance individual ability and quality. New media has become the main means of interpersonal communication in college. The new media has expanded the way and channel of college students' interpersonal communication, and provided more ideas and methods for college students to solve social problems.

\section{(4) Promote the diversification of management and teaching}

Mobile Internet era is the age of rapid development of large data. The hypertext link function of the network not only provides massive information for people, but also connects numerous pieces of information with large data. Mobile Internet support the use of multi-window operation with various types of mobile terminal equipment, the presentation of information is no longer limited to the text, but make the picture, video and sound into the information content. This large data makes people's reading anytime and anywhere, you can freely switch content that you interested in.

Colleges managers can use the new media platform to establish micro-public platform, the official micro blogging, make accurate and timely understanding of college students 'learning and living, make in-depth thinking 
and research for the representative and the universal hot issues of college students , show a wealth campus cultural life, and promote the spiritual and cultural construction of the campus. New media teaching can give full play to students' initiative. Teachers can through the new media platform make remote teaching and management, publish teaching plans, lectures, learning methods, post-homework assignments, achieve timely interaction with students, greatly improve the efficiency of student learning, and make effective statistics and analysis for the students' question.

\section{The Negative Influence of New Media on Campus Culture Construction (1) Make crisis of Ideological and moral}

Some wrong and decadent Western ideologies affect the college students, which is not conducive to the establishment of a harmonious campus. When the spiritual culture of the school is confused, the normal order of social development will be disrupted, so that our socialist core values and traditional culture will be affected. The spirit, morality, ideological behavior and other aspects of the student who is in the basic value formation period easily are affected.

\section{(2) Weakened the dominance of the traditional media}

New media can enable students to fully express their views and opinions, but also questioned the views of the authority, shaking the dominant position of the traditional media. New media expand the autonomy of students to receive information, leading college students easily to get more information, publish information and dissemination information. The diversification of information channels has led to the emergence of various ideas, which makes the effect of traditional ideological and political education weakened. It is not conducive to the construction of campus spiritual culture. Because there is no clear information dissemination of the main body, the religious way of ideological and political education will decline, which make dilemma to unify the correct guide the mainstream campus culture.

\section{(3) Increase the difficulty of education and management}

New media make college students accept more and more ideas, which also contain some contrary to the mainstream culture ideas. Because of the uncontrollability and uncertainty of these messages, some negative, decadent and backward ideological and ideological information is transmitted by the new media platform, which brings profound influence to college students and weaken the positive effect of ideological and political education in colleges. The result of this distraction is not only the impact of long reading and deep reading, but also it will bring this fragmented consciousness into people's lives, learning and work. That is, the adverse effects of fragmented reading is not limited to the field of reading, but also spread to other aspects of life.

Some people who lack basic media literacy at all costs create false news in order to obtain attention. People use the new media platform to express their views, make the second content of the dissemination of communication, reduce the individual's independent thinking space, affecting the individual's values, and even lead to confusion in values. The liberalization of network speech and the 
diversification communication forms of new media platforms have made the supervision of public opinion in the relevant regulatory departments more difficult and the effect of ideological and political education in colleges has been weakened.

\section{(4) Exacerbated the students of one-sided understanding}

Due to the limitations of the ideological and cognitive level of college students and the lack of practical experience, it is difficult to understand the truth and motivation behind things in a short time. The continuous emergence of network public opinion events also caused the decline of the moral concept of college students, which is not conducive to the healthy growth of their physical and mental.

\section{(5) Leading to interpersonal alienation and thinking ability decline}

Many people make communication with others by anonymous identity; undoubtedly dilute the reality between the feelings and relationships. When students are in a virtual world for a long time, lack of personal experience and contact, cannot make their own dialogue with the real world, prone to virtual and realistic separation, deepen the psychological loneliness, resulting in the relationship with the reality of the desalination of friends.

New media provides a wealth of learning resources for college students, but also makes the students depend on it frequency. When the student face to the problem, they make over-reliance on the search engine, leading the understanding, innovation, independent thinking ability of college students gradually weakened.

\section{Countermeasure of Perfecting Campus Culture Construction in New} Media Environment

(1) To achieve the new media and traditional media in the content, approach, management integration

The traditional media information dissemination of the professional and authoritative advantages makes up for the new media dissemination of information and the complexity to achieve the integration of media content. The traditional campus media mainly spread the mainstream values of the country, society and schools. Therefore, universities should pay attention to the authoritative and professional content of propagating content in the process of media integration.

Way integration is making the campus radio, promotional columns and new media integration, through the mobile phone, computer, and tablet terminal combination, to do real-time broadcast, real-time publicity, so that students receive the latest information on the campus. Only the effective integration of traditional media and new media can help the construction of campus media and then to promote the construction of campus culture.

The construction of the new media team should take the traditional media as the standard, establish a professional new media team, and form a joint force with the traditional media, guiding the campus public opinion, dissemination of social positive energy, improving the overall publicity and education efficiency. In the management process, we should take full advantage of the new media transmission advantages to make the effective combination of old and new media. 


\section{(2) Create a leading campus new media platform}

School every day push a innovative, deep, positive, dissemination of mainstream value of the message, achieve good interaction with students, and gradually realize the campus culture from traditional to innovative by web chat.

School regularly update micro blogging content, publishes school news, history and culture, campus life, employment information, and create a good learning atmosphere, guide students to cultivate the mainstream cultural awareness, so as to build an open, equal, authoritative ideological and political New platform for education through the official micro blogging.

(3) To strengthen the campus new media management system and team building

School can develop a series of feasible new campus media management system; form a professional, high-quality new media team. It should ensure that the contents are health and civilized by new media dissemination, so that the campus culture has good network environment.

(4) To strengthen the students' media literacy and mainstream culture of the correct guidance and education

Teachers can change the traditional classroom teaching model to the new media, analyze the social events on the new media platform, organize the online discussion, expand and consolidate the results of the classroom discussions through the topics and ways of planning discussions. Students should fully understand the opportunities and challenges of new media, improve their political quality, broad participation in social practice, improve their social responsibility; establish a firm ideals and beliefs, consciously practice the socialist core values, strengthen their ability to screen information, build their own good media literacy.

\section{Acknowledgement}

This paper is one of the research results of "News Media Integration Development and Innovation Research of Campus" (Project No.GD16XXW03), which is the "13th Five-Year Plan" of Guangdong Provincial Philosophy and Social Science in 2016.

\section{References}

[1] Cui Yue. New media of campus culture construction of the basic way [J]. School party building and ideological education. 2016 (05): 80-81.

[2] Geng Ru, Wang Huabiao, Gao Hongde.Study on the Thought and Countermeasure of Strengthening Campus Culture Construction in Colleges and Universities [J]. Education and Occupation. 2016 (21): 112-115.

[3] Jiang Guangxue, Zhang Yong, Xu Peng.Network information age university campus culture construction subject and subject construction [J]. School Party building and ideological education. 2016 (11): 71-74.

[4] Mao Haiyan. Full-media of university campus culture construction path [J]. JiangSu Higher Education. 2014 (06): 53-55. 